\title{
Non-Specific Abdominal Pain and Air Pollution: A Novel Association
}

\author{
Gilaad G. Kaplan ${ }^{1,2,39}$, Mieczyslaw Szyszkowicz ${ }^{4 * 9}$, Jakub Fichna”, Brian H. Rowe ${ }^{5}$, Eugeniusz Porada ${ }^{4}$, \\ Renaud Vincent ${ }^{4}$, Karen Madsen ${ }^{6}$, Subrata Ghosh ${ }^{1,2}$, Martin Storr ${ }^{1,2,8}$
}

1 Division of Gastroenterology, University of Calgary, Calgary, Alberta, Canada, 2 Departments of Medicine, University of Calgary, Calgary, Alberta, Canada, 3 Community Health Sciences, University of Calgary, Calgary, Alberta, Canada, 4 Environmental Health Sciences and Research Bureau, Health Canada, Ottawa, Ontario, Canada, 5 Department of Emergency Medicine and School of Public Health, University of Alberta, Edmonton, Alberta, Canada, $\mathbf{6}$ Department of Medicine, Division of Gastroenterology, University of Alberta, Edmonton, Alberta, Canada, 7 Department of Biomolecular Chemistry, Medical University of Lodz, Lodz, Poland, 8 Department of Medicine, Ludwigs-Maximilians University, Munich, Germany

\begin{abstract}
Background: We studied whether short-term exposure to air pollution was associated with non-specific abdominal pain in epidemiologic and animal studies.

Methods: Patients visiting the emergency department with non-specific abdominal pain were identified in Edmonton (1992 to $2002, n=95,173)$ and Montreal $(1997$ to $2002, n=25,852)$. We calculated the daily concentrations for ozone $\left(O_{3}\right)$, nitrogen dioxide $\left(\mathrm{NO}_{2}\right)$, sulfur dioxide $\left(\mathrm{SO}_{2}\right)$, carbon monoxide $(\mathrm{CO})$, and particles $<10\left(\mathrm{PM}_{10}\right)$ or $<2.5\left(\mathrm{PM}_{2.5}\right) \mu \mathrm{m}$. A case crossover study design was used to estimate the odds ratio (OR) and $95 \%$ confidence interval $(\mathrm{Cl})$ associated with an increase in the interquartile range of the air pollutants. We investigated differential effects by age and sex. Mice were gavaged with urban particle extracts. In animal models, colonic motility was tested, and visceral abdominal pain was measured using a writhing test, and behavioral response to oil of mustard and neostigmine. Motility and pain was measured acutely ( 1.5 hours after gavage) and chronically (7-days and 21-days after gavage).

Results: Emergency department visits for non-specific abdominal pain were primarily by women between the ages of 15-24 years. Individuals aged 15 to 24 years were at increased risk of non-specific abdominal pain in Edmonton (same day CO: $\mathrm{OR}=1.04,95 \% \mathrm{Cl}=1.02-1.06$; and $\left.\mathrm{NO}_{2}: \mathrm{OR}=1.06,95 \% \mathrm{Cl}=1.03-1.09\right)$. The risk of air pollution among $15-24$ year olds in Montreal was significantly positive (same day $\mathrm{CO}: \mathrm{OR}=1.11,95 \% \mathrm{Cl}=1.05-1.17 ; \mathrm{NO}_{2}: \mathrm{OR}=1.09,95 \% \mathrm{Cl}=1.01-1.16 ; \mathrm{SO}_{2}$ : $\left.\mathrm{OR}=1.17,95 \% \mathrm{Cl}=1.10-1.25 ; \mathrm{PM}_{2.5}: \mathrm{OR}=1.09,95 \% \mathrm{Cl}=1.04-1.15\right)$. Abdominal pain was increased by an acute gavage of pollution extract but not to chronic exposure to pollutants. Colonic transit was delayed following chronic but not acute exposure with the pollutants.
\end{abstract}

Conclusions: Epidemiological and animal data suggest that short-term exposure to air pollution may trigger non-specific abdominal pain in young individuals.

Citation: Kaplan GG, Szyszkowicz M, Fichna J, Rowe BH, Porada E, et al. (2012) Non-Specific Abdominal Pain and Air Pollution: A Novel Association. PLoS ONE 7(10): e47669. doi:10.1371/journal.pone.0047669

Editor: Devendra Amre, University of Montreal, Canada

Received April 8, 2012; Accepted September 18, 2012; Published October 31, 2012

Copyright: (c) 2012 Kaplan et al. This is an open-access article distributed under the terms of the Creative Commons Attribution License, which permits unrestricted use, distribution, and reproduction in any medium, provided the original author and source are credited.

Funding: Funding was provided by Health Canada and The Alberta IBD Consortium. The funders had no role in study design, data collection and analysis, decision to publish, or preparation of the manuscript.

Competing Interests: The authors have declared that no competing interests exist.

* E-mail: mietek.szyszkowicz@hc-sc.gc.ca

9 These authors contributed equally to this work.

\section{Introduction}

Abdominal pain is the second most common diagnosis (4.2\%) claimed by emergency department physicians in the USA. In many cases patients are diagnosed with non-specific abdominal pain, which refers to abdominal pain that is not explained during acute assessment. [1,2] While many patients diagnosed with nonspecific abdominal pain are asymptomatic at a later outpatient follow-up [3,4,5], a subset of these patients require recurrent admissions. [6,7,8] Consequently, non-specific abdominal pain is an important clinical presentation associated with impairment in quality of life for patients and significant costs to the health care system. $[7,8]$
The underlying cause of non-specific abdominal pain is likely multifactorial. non-specific abdominal pain may be due to gastrointestinal diseases such as Crohn's [9] and celiac [10] diseases that are diagnosed after the patient is discharged from the emergency department. Additionally, some patients experience a transient illness such as gastrointestinal infection. Cases of nonspecific abdominal pain may also represent a functional disorder such as irritable bowel syndrome. [11] Despite extensive research into the causes of non-specific abdominal pain, risk factors are not known and thus, exploration of triggers of non-specific abdominal pain is warranted. 
Air pollution directly effects pulmonary diseases (e.g. asthma) and has been associated with non-pulmonary diseases including cancer and strokes. [12,13,14] Recently, studies have indicated that air pollution may affect gastrointestinal disorders such as the inflammatory bowel diseases and appendicitis. [15,16] Air pollutants can cause systemic effects such as cardiovascular [17] or liver metabolic [18] changes after primary deposition and direct effects in the respiratory compartment. [19] However, most inhaled particles deposited in the nasopharyngeal compartment and airways are removed through mucociliary clearance and swallowed within a day [20] and thus, gastrointestinal effects may be due to direct effects of particles. [19]

Consequently, we investigated whether acute exposure to air pollutants was associated with emergency department visits for non-specific abdominal pain by: 1) evaluating the effect of shortterm ambient air pollution exposure in a human population; 2) replicating this epidemiological study in a second population; and 3) exploring the biological plausibility in in vitro and in vivo models.

\section{Methods}

\section{Phase 1: Epidemiological Studies}

Study Population. As described previously [21], the administrative database study was approved by the individual research ethics boards at each participating institution and the data were transferred to the Health Canada following de-identification. No patient contact was made and patients could not be traced. The International Classification for Disease $9^{\text {th }}$ revision was used to identify patients who were discharged from an emergency department with a primary diagnosis of non-specific abdominal pain $(789.0 \times)$. [2] First, we identified a population-based sample of 95,173 individuals who visited one of 5 emergency department in Edmonton for non-specific abdominal pain from 1992-2002. Second, we identified a replication study population of 25,852 individuals who visited a downtown emergency department in Montreal for non-specific abdominal pain from 1997-2002. Three digit postal codes were used to restrict the study population to residents of the city of Edmonton or Montreal. While the study population from Edmonton was population-based and included all ages, pediatric emergency department visits were underrepresented in Montreal because of the immediate proximity of a Pediatric Hospital. Thus, for the study population from Montreal the analysis was restricted to individuals over the age of 15 years.

Air Pollution and Meteorological Data. The air pollutants measured included sulfur dioxide $\left(\mathrm{SO}_{2}\right)$, nitrogen dioxide $\left(\mathrm{NO}_{2}\right)$, carbon monoxide $\mathrm{CO}$, ozone $\left(\mathrm{O}_{3}\right)$, and particulate matter characterized by an aerodynamic diameter of $\leq 10 \mu \mathrm{m}\left(\mathrm{PM}_{10}\right)$ and of $\leq 2.5 \mu \mathrm{m}\left(\mathrm{PM}_{2.5}\right)$. The data on air pollution were supplied by Environment Canada from fixed monitoring stations in Edmonton and Montreal. Environment Canada also supplied hourly data for temperature and relative humidity. For each air pollutant and weather variable, we obtained data on 24 measurements carried out at the monitoring station at hourly intervals. If more than 6 measurements were missing for a specific day, than the data for this monitor was considered as missing. An average was calculated for each monitor to represent daily mean value and average among monitors was used to represent ambient exposure across the city. [22] The distribution of air pollution and weather monitors for both cities can be found in Environment Canada's website. [23] A detailed description of air pollutant and weather measurements, monitor distribution, and correlations among monitors has been previously reported. [24]

Statistical Analysis. We applied a case crossover study design, which is an adaptation of the case-control study whereby cases serve as their own controls. [25] A time-stratified design was used to select referent periods, whereby the referent periods were selected from the same day of the week, month and year as the case's date of hospital visit. Because within-individual comparisons were made, confounding due to time-independent risk factors (e.g. genetics) was reduced. Similarly, the matching of control to case periods by day of week controlled for the influence of "day of week" effects. [25]

We used a conditional logistic regression (subroutine PHREG in SAS) to model the air pollutants and 6 components for natural splines for temperature and relative humidity. Estimates were expressed as the odds ratio (OR) with 95\% confidence intervals (CI) associated with an increase in the interquartile range of the air pollutants $\left(\mathrm{SO}_{2}, \mathrm{NO}_{2}, \mathrm{CO}, \mathrm{O}_{3}, \mathrm{PM}_{10}\right.$, and $\left.\mathrm{PM}_{2.5}\right)$ after adjusting for temperature and relative humidity. Control for potentially nonlinear effects of weather was achieved by including natural spline functions of temperature and relative humidity. The interquartile range was calculated based on the daily mean concentration of each air pollutant during the study period (Table S1). Analyses were performed separately for Edmonton and Montreal. Additionally, the analysis was stratified by: age, categorized as $<15$ (only Edmonton), 15-24, 25-34, 35-44, 45-64, and >64 years. Different time lags for pollution and weather exposures were used in our analyses including same day, one day before admission (i.e. 1-day lag), and two days before admission (i.e. 2-day lag). Among individuals 15 to 24 years of age we examined for effect modification by sex by incorporating an interaction term (e.g. $\mathrm{PM}_{2.5} \mathrm{X}$ sex) into the model. All statistical analyses were conducted in SAS (version 8, SAS, Cary, North Carolina, US).

\section{Phase 2: In Vitro \& In Vivo Studies}

Animals. Male Swiss albino mice (CD1, Charles River, Canada), weighing 24-26 g, were used. The animals were housed at a constant temperature $\left(22^{\circ} \mathrm{C}\right)$ and maintained under a 12 -h light/dark cycle with free access to laboratory chow and tap water. Animal use was approved by the University of Calgary Animal Care Committee.

Particulate Matter Preparation. The urban particles EHC-6802 consisted of a blend of total suspended particulate matter recovered from filters of the single-pass air purification system at the Environmental Health Centre (Tunney's Pasture, Ottawa, ON) in 1996, 1998, 2000, and 2002, as described previously. [26] Particles were mechanically sieved using a $36 \mu \mathrm{m}$ mesh filter, and combined in equal proportions. EHC-6802 was recovered at the same site and manner as the urban particles EHC-93, and chemical characterization of the EHC-6802 material has confirmed that it was equivalent to the EHC-93 material. [26]

Experimental Design. Animals were randomly assigned to two groups with the same number of animals per treatment group: control (oral tap water, $200 \mu \mathrm{l}$ /animal, once daily; $\mathrm{n}=8$ ) or EHC6802 (oral $360 \mu \mathrm{g} / 200 \mu \mathrm{l}$ tap water/animal, once daily; $\mathrm{n}=8$ ). Gavages were given once daily and experiments were performed in the following protocols: 1) $1.5 \mathrm{~h}$ after the gavage; 2) daily for 7 days; and 3) daily for 21 days.

Isolated smooth muscle strips. Full-thickness segments $(1 \mathrm{~cm})$ of ileum and distal colon were resected. The preparations were mounted between two platinum electrodes and placed longitudinally in separate organ baths as described previously. [27] One end of each preparation was attached to the bottom of the organ bath, while the other end was connected to a FT03 force displacement transducer (Grass Technologies, West Warwick, RI, USA). Changes in tension were amplified by a P11T amplifier 
(Grass Technologies) and recorded on a computer using PolyView software (Polybytes, Cedar Rapids, Iowa).

Electrical field stimulation (EFS; $8 \mathrm{~Hz} ; 60 \mathrm{~V}$; pulse duration $0.5 \mathrm{~ms}$; train duration $10 \mathrm{sec}$ ) was applied by a S88X stimulator (Grass Technologies). EFS of isolated smooth muscle strips caused twitch contractions, which were of cholinergic neuronal origin as they were virtually abolished by atropine $\left(10^{-6} \mathrm{M}\right)$ or TTX $\left(10^{-6} \mathrm{M}\right)$ (data not shown). In separate experiments the response of ileal and colonic muscle strips to direct muscular activation with stepwise addition of bethanechol $\left(10^{-7} \mathrm{M}-3 \times 10^{-5} \mathrm{M}\right)$ was recorded.

EHC-6802 urban ambient particles were added cumulatively into the organ baths and effects on the EFS-induced contractions were recorded. The mean amplitude of 4 successive twitch contractions was used as an internal control. Changes in contractions were reported as the percentage of the internal control. In control experiments the effects of the vehicle (tap water) were tested to control against possible effects on contractility by adding vehicle..

In separate experiments the response of ileal and colonic muscle strips to (i) neuronal electrical stimulation and (ii) direct muscular activation with stepwise addition of bethanechol $\left(10^{-7} \mathrm{M}-\right.$ $3 \times 10^{-5} \mathrm{M}$ ) was recorded following $90 \mathrm{~min}, 7$ days and 21 days following oral treatment with EHC-6802 particles.

Golonic expulsion test. Distal colonic expulsion was measured as reported previously. [27] 1.5 hours after receiving tap water (control) or EHC-6802 particle suspension ( $\mathrm{n}=5-10)$, a glass bead $(2 \mathrm{~mm})$ was inserted $2 \mathrm{~cm}$ into the distal colon and the time to bead expulsion was determined.

Behavioural Pain Responses. Behavioural pain responses were tested in 3 models used to study abdominal visceral pain responses $(n=5-10)$. The writhing test was performed as described by Gach et al. [28] Ninety minutes after oral administration of tap water (control group) or EHC-6802 particle suspension, mice received an intraperitoneal (i.p.) injection $(10 \mathrm{ml} / \mathrm{kg})$ of acetic acid solution $(0.5 \%)$. The total number of writhes was counted 5 minutes after acetic acid injection, during three periods lasting 5 minutes each. The writhing response, considered as a nociceptive behaviour, was characterized by elongation of the body and the development of tension in the abdominal muscles and hind paws.

Behavioural responses to intracolonic (i.c.) oil of mustard $(\mathrm{OM})$ and i.p. neostigmine were determined based on Laird et al. [29] and Eijkelkamp et al. $(n=5-10)$. [30] For the assessment of the OM-induced pain behaviours, $50 \mu \mathrm{l}$ of OM $(1 \%$ in $70 \%$ ethanol$30 \%$ saline) was administered i.c. under isoflurane anaesthesia. Petroleum jelly was applied to the perianal area to avoid stimulation of somatic areas. After 5 min of recovery, spontaneous behaviours were videotaped for analysis by an observer blinded to the experimental conditions.

In a separate experiment, neostigmine $(2.5 \mu \mathrm{g} / \mathrm{kg})$ or vehicle was administered i.p. and the pain-related behaviours were counted over a 10 minute period after the injection. Postures defined as pain-related behaviours: 1) licking of the abdomen, 2) stretching the abdomen, 3) squashing of lower abdomen against the floor, and 4) abdominal retractions, were each counted as 1.

Statistical Analysis. Statistical and curve-fitting analyses were performed using Prism 4.0 (GraphPad Software Inc., La Jolla, CA, USA). The data are expressed as means \pm standard deviation. Student's t-test compared treatment means with control means. Two-sided P-values $\leq 0.05$ were statistically significant.

\section{Results}

\section{Phase 1: Epidemiological Studies}

Nearly 2/3 of emergency department visits for non-specific abdominal pain were by women and the majority of women presented in adolescence and early adulthood (Figure 1A and 1B; Table S1). In Edmonton, where pediatric emergency department visits were available, $61.4 \%$ of emergency department visits for non-specific abdominal pain occurred before the age 34 years. In Montreal, patients between the ages of 15 and 34 years accounted for $36.7 \%$ of emergency department visits (Table S1).

Table S2 describes the mean daily concentrations and variance of each air pollutant during the study periods. The effect of air pollution exposure was only observed when ages were stratified. In Edmonton, individuals aged 15 to 24 years were at elevated risk for presenting to the emergency department on the same day of higher concentrations of $\mathrm{CO}(\mathrm{OR}=1.04,95 \% \mathrm{CI}=1.02-1.06)$, $\mathrm{NO}_{2}(\mathrm{OR}=1.06,95 \% \mathrm{CI}=1.03-1.09), \mathrm{SO}_{2}(\mathrm{OR}=1.02,95 \%$ $\mathrm{CI}=1.00-1.04)$, and $\mathrm{PM}_{2.5}(\mathrm{OR}=1.03,95 \% \mathrm{CI}=1.00-1.05)$. Similar effects were observed in Montreal for $\mathrm{CO}(\mathrm{OR}=1.11$, $95 \% \mathrm{CI}=1.05-1.17), \mathrm{NO}_{2}(\mathrm{OR}=1.09,95 \% \mathrm{CI}=1.01-1.16)$, $\mathrm{SO}_{2}(\mathrm{OR}=1.17,95 \% \mathrm{CI}=1.10-1.25)$, and $\mathrm{PM}_{2.5}(\mathrm{OR}=1.09$, $95 \%$ CI $=1.04-1.15$ ) (Table 1). Among 15 to 24 year olds, $\mathrm{O}_{3}$ was negatively associated with emergency department visits for non-
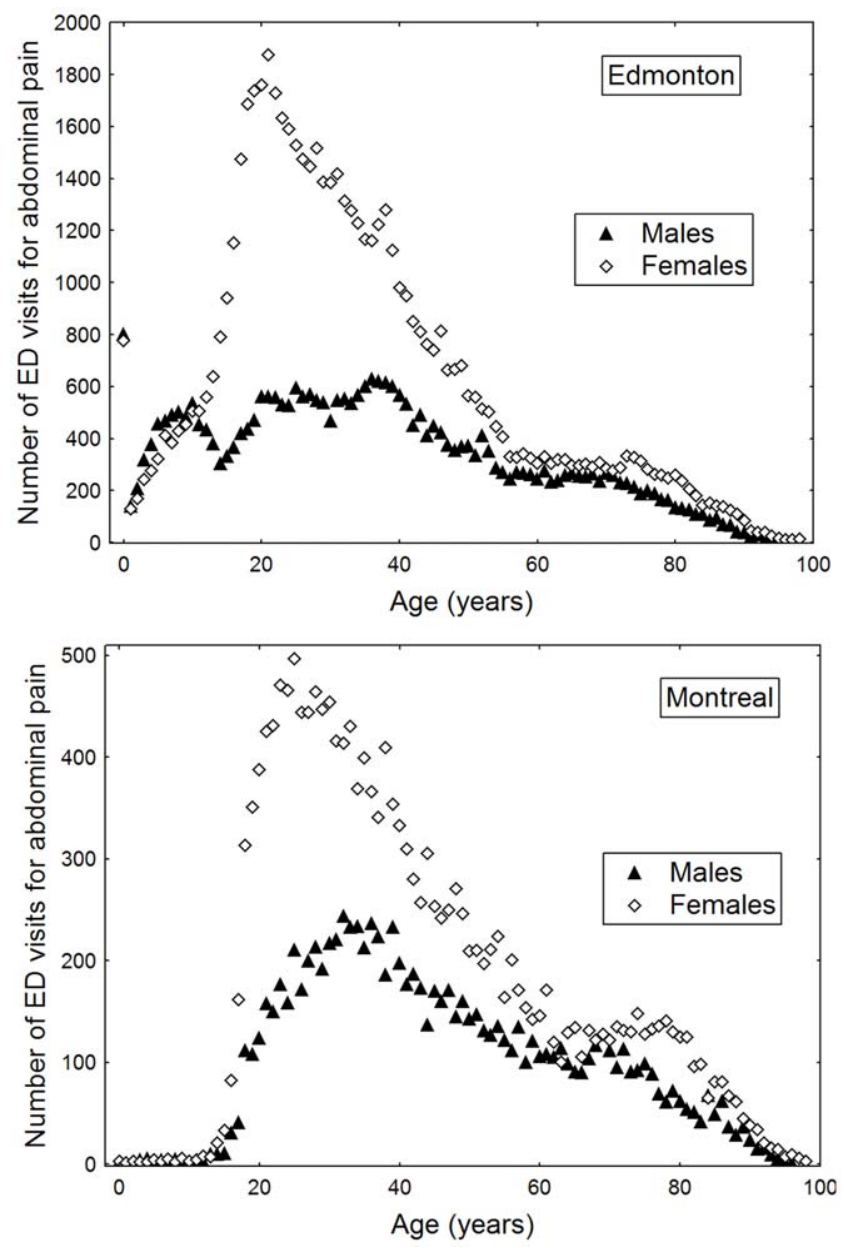

Figure 1. Age-specific frequency of admissions to emergency departments (ED) for non-specific abdominal pain stratified by sex.

doi:10.1371/journal.pone.0047669.g001 
specific abdominal pain in Edmonton $(\mathrm{OR}=0.95, \quad 95 \%$ $\mathrm{CI}=0.91-0.99), \quad$ but not in Montreal (OR $=1.03, \quad 95 \%$ CI $=0.95-1.11) \quad$ (Table 1). The effect of air pollutants on individuals aged 15 to 24 stratified by sex are presented in Table 2. Interaction terms were not significant between sexes (Table 2). The effect of air pollutants with 1-day and 2-day lags stratified by age and sex are presented in Tables S3 and S4, respectively.

\section{Phase 2: In Vitro \& In Vivo Studies}

The course of body weight was not significantly different in animals treated with EHC-6802 urban particles by gavage compared to vehicle treated mice (Figure S1).

Gastrointestinal Motility. EHC-6802 (1:100000-1:1) produced a significant, concentration-dependent inhibitory effect on the EFS $(8 \mathrm{~Hz})$-induced twitch contractions in the colon, but not the mouse ileum (Figure 2A). Electrically induced contractions were not changed at any time points (90 min, 7 days, 21 days), compared to bethanechol $\left(10^{-6} \mathrm{M}\right)$ treatment (Figure S2). Responses to direct muscular activation with bethanechol $\left(10^{-7} \mathrm{M}-3 \times 10^{-5} \mathrm{M}\right)$ were not changed by adding EHC-6802 particles to the organ bath (Figure S1C) at any time point (Figure S2).

In the colonic expulsion test a 7-day treatment with EHC-6802 particles significantly reduced the time to bead expulsion (Figure 2B). Neither acute $(1.5 \mathrm{~h})$ nor chronic (21 days) treatment with EHC-6802 significantly affected the colonic bead expulsion time.

Nociception. In our preliminary experiments, we confirmed that the i.p. injection of acetic acid solution, i.c. instillation of OM, and the i.p. injection of neostigmine induced pain behaviors in naive mice (data not shown). The acute administration of EHC6802 (1.5 h treatment) significantly increased the number of writhes compared to control group (Figure 3A). 7-day (Figure 3A) and 21-day (data not shown) treatment with EHC-6802 did not modify the response to acetic acid. EHC-6802 administered at 1.5 hour also showed a significantly higher number of spontaneous pain-related behaviours induced by OM (Figure 3B) and neostigmine (Figure 3C), compared to mice after 7- and 21-day treatment (21 days, data not shown).

\section{Discussion}

Non-specific abdominal pain is a common clinical presentation to the emergency department, typically involves multiple investigations, and may require admission to hospital. [1] A cause is often not discovered during emergency department visit and in most cases a subsequent organic diagnosis is not made during outpatient follow-up. [3] Although non-specific abdominal pain is a common disorder of the young [31,32], triggers of acute pain are not known. We found that young individuals had the highest prevalence of non-specific abdominal pain and were significantly more likely to visit the emergency department for non-specific abdominal pain when indicators of air pollution were elevated. Furthermore, ingestion of EHC-6802 urban ambient particles by mice led to an acute exacerbation of pain, which did not persist after chronic exposure of the pollutants to the animal. These observations suggest a novel association between air pollution exposure and exacerbation of abdominal pain.

In both Edmonton and Montreal, $\mathrm{CO}, \mathrm{PM}_{2.5}, \mathrm{SO} 2$, and $\mathrm{NO}_{2}$ were associated with non-specific abdominal pain presentations in individuals aged 15 to 24 years. However, $\mathrm{PM}_{10}$ was positively associated with non-specific abdominal pain in Edmonton, but null in Montreal. Furthermore, ozone was negatively associated with non-specific abdominal pain in Edmonton, but not in Montreal. Additionally, the risk estimates were generally higher in Montreal than in Edmonton. The heterogeneity of findings between cities may be explained by residents living and/or working in downtown Montreal having greater exposure to air pollutants. In contrast, residents living throughout Edmonton would have been exposed to a wider range of air pollution concentrations. The greater patient-level variability to air pollution exposure experienced in Edmonton may have resulted in nondifferential misclassification that would have the effect of biasing the risk estimates towards the null. Furthermore, the fixed monitoring stations are located to represent the background air pollution concentrations in a city; however, misclassifying the air pollution exposure may occur when multiple fixed monitoring sites are averaged into one daily value for the entire city. [22] Thus, future multi-city studies are required to confirm the associations observed in our study and to explore causes of heterogeneity.

Young women are known to have the highest prevalence of non-specific abdominal pain. [31,32] In both Edmonton and Montreal, women aged 15 to 24 years were more likely to visit an emergency department for non-specific abdominal pain. The reason for the disproportionate occurrence of non-specific abdominal pain in women as compared to men is not clear. Abdominal pain may be exacerbated during the menstrual cycle. [33] Furthermore, women have been shown to be more likely to seek medical attention for abdominal pain when compared to men. [34,35] We did not observe effect modification between men and women aged 15 to 24 years, suggesting that the effect of air pollution on non-specific abdominal pain was not sex-specific. However, because the risk estimates observed in our study were modest, we may have not been adequately powered to detect effect modification by sex.

The mechanism by which air pollutants may exacerbate abdominal pain is not known. In one study high concentrations of air pollutants $\left(\mathrm{NO}_{2}, \mathrm{CO}\right.$, and $\left.\mathrm{O}_{3}\right)$ impaired gastric basal contractility. [36] However, low-level exposures were not associated with gastric dysmotility. [36] Another study demonstrated that animals fed EHC-6802 had increased IL-8 secretion from the small bowel and experienced changes in the composition of colonic microflora. [37] Our in vitro studies demonstrated impaired colonic, but not ileal, contractility after the acute exposure of the ex-vivo tissue with the particulate matter. Neuronally mediated contractility was impaired whereas the direct smooth muscular reactivity was unchanged suggesting that the observed effects involved neuronal rather than muscular mechanisms. In vivo reduction of colonic motility was not observed acutely, but a significantly slowed colonic motility was recorded after 7 days, but not after 21 days of daily exposure to the EHC-6802 particles. Overall in vitro and in vivo effects on intestinal motility by acute and chronic exposure to EHC-6802 particles were negligible.

In contrast, acute exposure to EHC-6802 particles led to significantly increased pain response in mice and this observation was consistent in 3 different behavioral tests of visceral abdominal pain. Chronic exposure to ingested pollutants did not affect the pain response models suggesting that pain adaptation to the pollutants may have occurred over time. The cause for the acute hypersensitivity in mice is not known. The animal studies suggest that the pain response following acute exposure to the pollutants were not driven by intestinal dysmotility. Exposure to air pollution may exacerbate systemic inflammation [38] or lead to oxidative damage of colonic mucosa. [39] Furthermore, air pollution has been shown to mediate dysfunction of endothelial-dependent vasodilation [40] that may contribute to visceral hypersensitivity. Future studies will be needed to explore the exact mechanisms and 


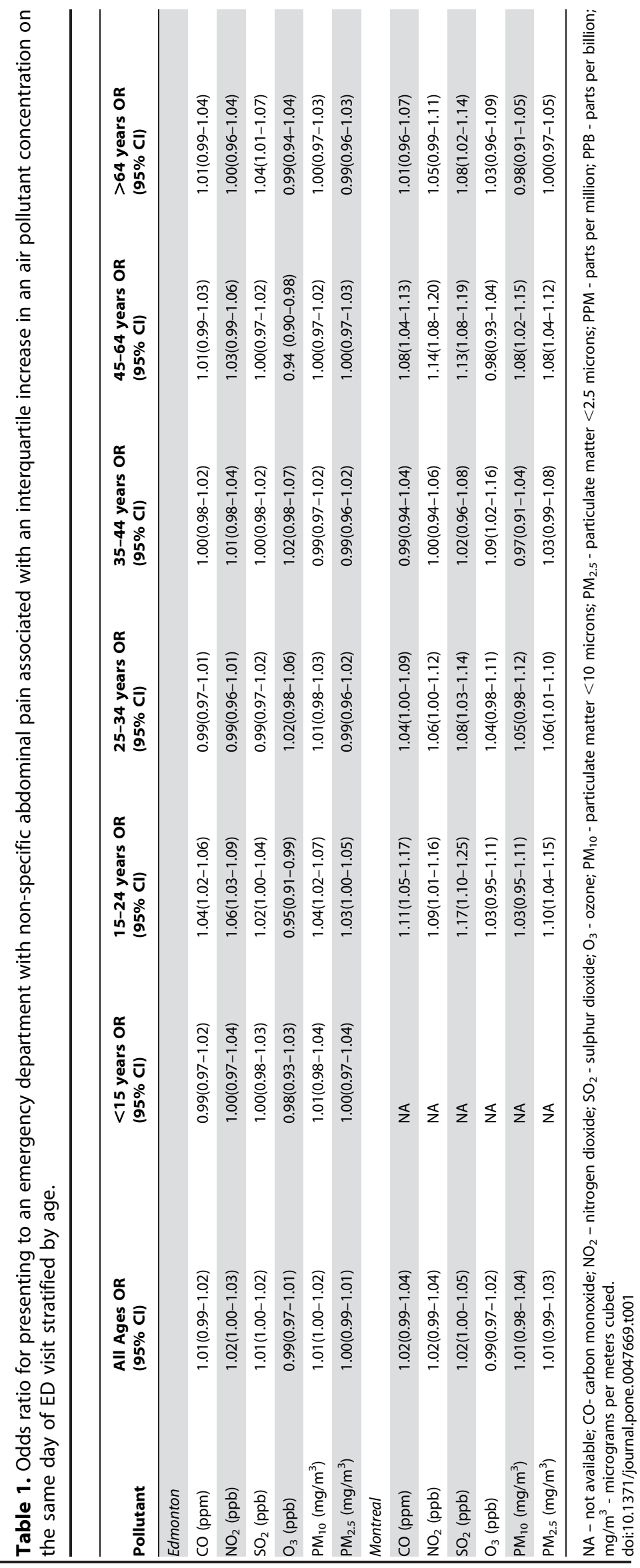


Table 2. Odds ratio for presenting to an emergency department with non-specific abdominal pain associated with an interquartile increase in an air pollutant concentration on the same day of ED visit stratified by gender among individuals aged 15-24 years.

\begin{tabular}{|c|c|c|c|c|c|c|}
\hline \multirow[b]{2}{*}{ Pollutant (unit) } & \multicolumn{3}{|l|}{ Edmonton } & \multicolumn{3}{|l|}{ Montreal } \\
\hline & $\begin{array}{l}\text { Males OR } \\
(95 \% \mathrm{Cl})\end{array}$ & $\begin{array}{l}\text { Females OR } \\
(95 \% \mathrm{Cl})\end{array}$ & p-Value for Interaction & $\begin{array}{l}\text { Males OR } \\
(95 \% \mathrm{CI})\end{array}$ & $\begin{array}{l}\text { Females OR } \\
(95 \% \mathrm{Cl})\end{array}$ & p-Value for Interaction \\
\hline $\mathrm{CO}(\mathrm{ppm})$ & $0.99(0.95-1.03)$ & $1.05(1.03-1.08)$ & 0.05 & $1.09(0.96-1.24)$ & $1.10(1.03-1.18)$ & 0.57 \\
\hline $\mathrm{NO}_{2}(\mathrm{ppb})$ & $1.00(0.94-1.06)$ & $1.08(1.04-1.11)$ & 0.07 & $1.06(0.91-1.22)$ & $1.09(1.01-1.18)$ & 0.10 \\
\hline $\mathrm{SO}_{2}(\mathrm{ppb})$ & $1.02(0.98-1.06)$ & $1.03(1.00-1.05)$ & 0.78 & $1.16(1.03-1.31)$ & $1.14(1.07-1.23)$ & 0.85 \\
\hline $\mathrm{O}_{3}$ (ppb) & $1.01(0.93-1.09)$ & $0.93(0.89-0.98)$ & 0.18 & $1.03(0.90-1.20)$ & $1.02(0.93-1.12)$ & 0.10 \\
\hline $\mathrm{PM}_{10}\left(\mathrm{mg} / \mathrm{m}^{3}\right)$ & $1.04(1.00-1.09)$ & $1.04(1.02-1.07)$ & 0.66 & $1.00(0.83-1.21)$ & $1.02(0.93-1.11)$ & 0.26 \\
\hline $\mathrm{PM}_{2.5}\left(\mathrm{mg} / \mathrm{m}^{3}\right)$ & $1.06(1.01-1.11)$ & $1.02(0.99-1.05)$ & 0.07 & $1.09(0.98-1.21)$ & $1.09(1.03-1.15)$ & 0.62 \\
\hline
\end{tabular}

$\mathrm{OR}$ - odds ratio; $\mathrm{Cl}$ - confidence interval; $\mathrm{CO}$ - carbon monoxide; $\mathrm{NO}_{2}$ - nitrogen dioxide; $\mathrm{SO}_{2}$ - sulphur dioxide; $\mathrm{O}_{3}$ - ozone; $\mathrm{PM}_{10}$ - particulate matter $<10$ microns; $\mathrm{PM}_{2.5}$ - particulate matter $<2.5$ microns; PPM - parts per million; PPB - parts per billion; $\mathrm{mg} / \mathrm{m}^{3}$ - micrograms per meters cubed.

doi:10.1371/journal.pone.0047669.t002

the associated neuronal circuits involved in triggering abdominal pain.

Several limitations should be considered. First, regional estimates of air pollutants from fixed monitoring stations may not reflect the variability of patient-level exposure to air pollutants.
Though, the effects of air pollutants were likely underestimated as measurement errors were presumably non-differential. Second, we attempted to control for confounding through the use of a case crossover study design whereby cases served as their own control; however, residual confounding may have influenced our estimates.

A
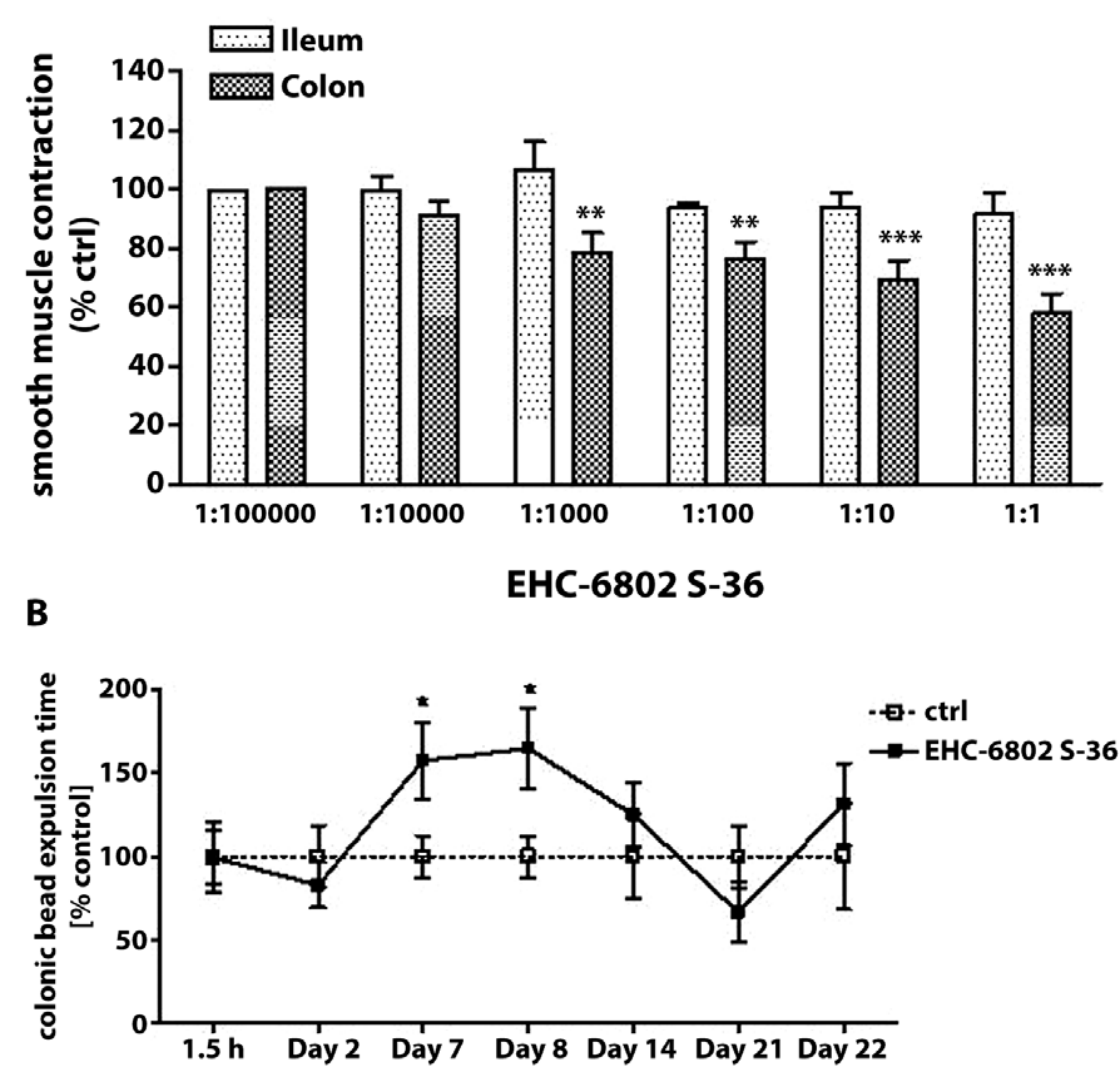

Figure 2. The effect of EHC-6802 on mouse GI motility. A) The effect of EHC-6802 (initial concentration $360 \mu \mathrm{g} / 200 \mu \mathrm{l}$ regarded as 1:1 dilution) on EFS ( $8 \mathrm{~Hz}$ )-stimulated smooth muscle contractions in mouse ileum and colon. Note that EHC-6802 significantly, in a concentration-dependent manner inhibited twitch contractions in mouse colon. Data represent mean $\pm S E M$ for $n=8$. ${ }^{*} \mathrm{P}<0.05$, as compared with control. B) In vivo effects of EHC-6802 (360 $\mu \mathrm{g} / 200 \mu \mathrm{l} / \mathrm{animal}, \mathrm{QD}, \mathrm{p} .0$.$) on colonic bead expulsion time in mice. The results are shown as mean \pm \mathrm{SEM}$ of $\mathrm{n}=5-10 \mathrm{mice}$ for each experimental group. ${ }^{*} \mathrm{P}<0.05$, as compared with control (animals receiving tap water).

doi:10.1371/journal.pone.0047669.g002 
A

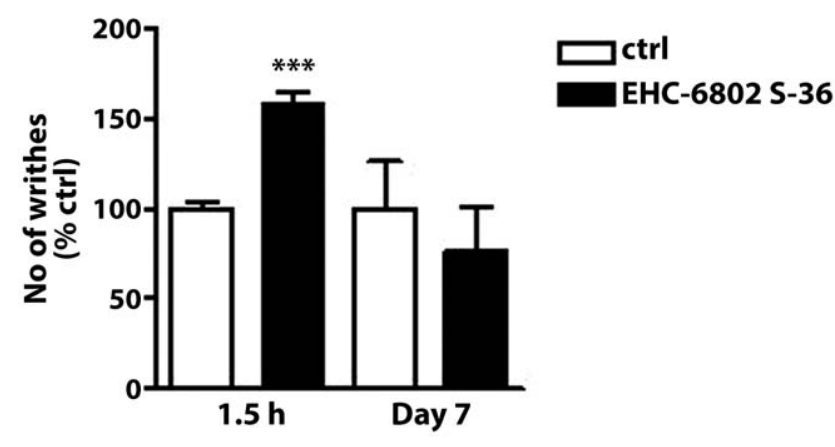

B

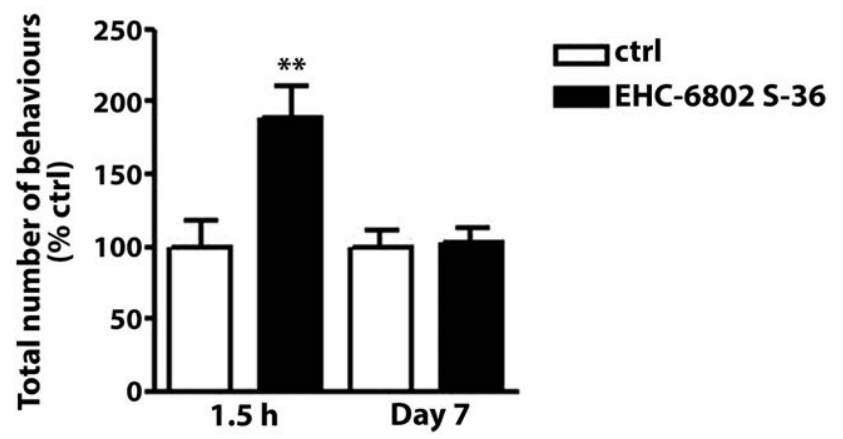

Figure 3. The effect of EHC-6802 $(360 \mu \mathrm{g} / 200 \mu \mathrm{l} / \mathrm{animal}$, p.o.) on behavioural pain responses in mice. A) The effect of EHC-6802 in the writhing test in mice. The number of writhes was determined $5 \mathrm{~min}$ after acetic acid injection $(0.5 \%, 10 \mathrm{ml} / \mathrm{kg}$, i.p.) over a period of $15 \mathrm{~min}$. Note that a single $1.5 \mathrm{~h}$ - treatment with EHC-6802 significantly increased the total number of writhes. Data represent mean \pm SEM of 5-10 mice per group. ${ }^{* * *} \mathrm{P}<0.001$, as compared to control (animals receiving tap water). B) The effect of EHC-6802 on the number of painrelated behaviours (licking of abdomen, stretching, squashing, abdominal contractions) evoked by i.c. administration of oil of mustard ( $1 \%$ in $70 \% \mathrm{EtOH}-30 \%$ saline), determined over a period of $20 \mathrm{~min}$. Note that a single $1.5 \mathrm{~h}$ - treatment with EHC-6802 significantly increased the number of pain-related behaviours. Data represent mean \pm SEM of 510 mice per group. ${ }^{* *} \mathrm{P}<0.01$, as compared to control (animals receiving tap water). C) The effect of EHC-6802 on the number of pain-related behaviours (licking of abdomen, stretching, squashing, abdominal contractions) evoked by the i.p. administration of neostigmine $(2.5 \mu \mathrm{g} /$ $\mathrm{kg}$ ), determined over a period of $10 \mathrm{~min}$. Note that a single $1.5 \mathrm{~h}$ treatment with EHC-6802 significantly increased the number of painrelated behaviours. Data represent mean \pm SEM of 5-10 mice per group. ${ }^{* *} \mathrm{P}<0.01$, as compared to control (animals receiving tap water). doi:10.1371/journal.pone.0047669.g003

For example aeroallergens, which may correlate with air pollution [41], were not evaluated in this study; however, aeroallergens are not known to trigger non-specific abdominal pain. Third, associations were explored in multiple pollutants using several lagged exposures, and stratified to investigate several factors (e.g. age groups). Thus, the probability of observing statistically significant findings by chance is increased. We attempted to minimize multiple comparison errors by including a replication study population and primarily reporting on associations observed in both populations. However, future studies are necessary to confirm our findings. Fourth, some of the non-specific abdominal pain patients may have had an unrecognized organic disease that was diagnosed after discharge from the emergency department.
For example, $\mathrm{NO}_{2}$ exposure (i.e., traffic pollutant) was associated with the development of appendicitis. [15] Furthermore, individuals less than 24 years and living in areas of higher concentration of $\mathrm{NO}_{2}$ were at a two-fold increased risk of developing Crohn's disease. [16] Because our risk estimates were modest in size, our findings may reflect significant associations among a specific gastrointestinal disorder (e.g., Crohn's disease). Nonetheless, discovering a possible link between air pollution exposure and gastrointestinal disease is an important finding that should motivate further research. Finally, while EHC-6802 particles have been validated to represent daily city exposure of air pollutants [26], our findings should be interpreted cautiously because EHC6802 particles were gathered in Ottawa and consists of multiple air pollutants.

In conclusion, individuals aged 15 to 24 years were most likely to present to emergency departments with non-specific abdominal pain and this occurred more frequently when the concentration of $\mathrm{CO}, \mathrm{PM}_{2.5}, \mathrm{SO} 2$, and $\mathrm{NO}_{2}$ were elevated in the atmosphere. These findings were observed in a population-based study in Edmonton and replicated in an urban downtown emergency department in Montreal. Additionally, we demonstrated that acute exposure to ingested EHC-6802 particles exacerbated abdominal pain in mice, a response that led to adaptation after chronic exposure. The consistency of the epidemiological and animal studies suggests that air pollution may trigger non-specific abdominal pain in some cases. Thus, future patient-level and basic laboratory studies should be performed to substantiate the findings, further explore possible underlying mechanisms, and identify at risk populations.

\section{Supporting Information}

Figure S1 A) In vivo effects of EHC-6802 (360 $\mu \mathrm{g} / 200 \mu \mathrm{l} /$ animal, QD, p.o.) or tap water $(200 \mu \mathrm{l} /$ animal, QD, p.o.) during a 21 day treatment course. B) EFS $(8 \mathrm{~Hz})$-stimulated smooth muscle contractions in mouse colon were not changed following $90 \mathrm{~min}, 7$ days or 21 days of treatment with EHC-6802 S-36, as compared to vehicle treated mice. C) Bethanechol $\left(10^{-7} \mathrm{M}-3 \times 10^{-5} \mathrm{M}\right)$ stimulated smooth muscle contractions in mouse ileum (left) and colon (right) were not changed when EHC-6802 $(360 \mu \mathrm{g} / 200 \mu \mathrm{l})$ was added to the organ bath.

(TIF)

Figure S2 Bethanechol $\left(10^{-7} \mathrm{M}-3 \times 10^{-5} \mathrm{M}\right)$ stimulated smooth muscle contractions in mouse ileum and colon were not changed following $90 \mathrm{~min}, 7$ days or 21 days of treatment with EHC-6802 S-36, as compared to vehicle treated mice.

(TIF)

Table S1 Frequency of emergency department visits for non-specific abdominal pain by age group and gender, Edmonton (EDM) and Montreal (MON).

(DOCX)

Table S2 Frequency distribution of the daily concentrations of ambient air pollutants and meteorological factors from April 01, 1992 to March 31, 2002 in Edmonton and January 01, 1997 to December 31, 2002 in Montreal.

(DOCX)

Table S3 Odds ratio for presenting to an emergency department with non-specific abdominal pain associated with an interquartile increase in an air pollutant concentration stratified by age for 1- and 2-day lags. NA - not available; $\mathrm{CO}$ - carbon monoxide; $\mathrm{NO}_{2}$ - nitrogen dioxide; 
$\mathrm{SO}_{2}$ - sulphur dioxide; $\mathrm{O}_{3}$ - ozone; $\mathrm{PM}_{10}$ - particulate matter $<10$ microns; $\mathrm{PM}_{2.5}$ - particulate matter $<2.5$ microns; PPM parts per million; $\mathrm{PPB}$ - parts per billion; $\mathrm{mg} / \mathrm{m}^{3}$ - micrograms per meters cubed.

\section{(DOCX)}

Table S4 Odds ratio for presenting to an emergency department with non-specific abdominal pain associated with an interquartile increase in an air pollutant concentration for 1- and 2-day lag stratified by gender among individuals aged 15-24 years. OR - odds ratio; CI confidence interval; $\mathrm{CO}$ - carbon monoxide; $\mathrm{NO}_{2}-$ nitrogen dioxide; $\mathrm{SO}_{2}$ - sulphur dioxide; $\mathrm{O}_{3}$ - ozone; $\mathrm{PM}_{10}$ - particulate matter $<10$ microns; $\mathrm{PM}_{2.5}$ - particulate matter $<2.5$ microns; PPM - parts per million; PPB - parts per billion; $\mathrm{mg} / \mathrm{m}^{3}$ micrograms per meters cubed.

(DOCX)

\section{References}

1. Sanders DS, Azmy IA, Hurlstone DP (2006) A new insight into non-specific abdominal pain. Ann R Coll Surg Engl 88: 92-94.

2. Nawar EW, Niska RW, Xu J (2007) National Hospital Ambulatory Medical Care Survey: 2005 emergency department summary. Adv Data: 1-32.

3. Jess P, Bjerregaard B, Brynitz S, Holst-Christensen J, Kalaja E, et al. (1982) Prognosis of acute nonspecific abdominal pain. A prospective study. Am J Surg 144: $338-340$

4. O’Byrne JM, Dempsey CB, O’Malley MK, O’Connell FX (1991) Non-specific abdominal pain in pre-menopausal women. Ir J Med Sci 160: 344-346.

5. Lukens TW, Emerman C, Effron D (1993) The natural history and clinical findings in undifferentiated abdominal pain. Ann Emerg Med 22: 690-696.

6. Decadt B, Sussman L, Lewis MP, Secker A, Cohen L, et al. (1999) Randomized clinical trial of early laparoscopy in the management of acute non-specific abdominal pain. Br J Surg 86: 1383-1386.

7. Raheja SK, McDonald PJ, Taylor I (1990) Non-specific abdominal pain-an expensive mystery. J R Soc Med 83: 10-11.

8. Sheridan WG, White AT, Havard T, Crosby DL (1992) Non-specific abdominal pain: the resource implications. Ann R Coll Surg Engl 74: 181-185.

9. Dubinsky MC, Johanson JF, Seidman EG, Ofman JJ (2002) Suspected inflammatory bowel disease-the clinical and economic impact of competing diagnostic strategies. Am J Gastroenterol 97: 2333-2342.

10. Sanders DS, Hopper AD, Azmy IA, Rahman N, Hurlstone DP, et al. (2005) Association of adult celiac disease with surgical abdominal pain: a case-control study in patients referred to secondary care. Ann Surg 242: 201-207.

11. Doshi M, Heaton KW (1994) Irritable bowel syndrome in patients discharged from surgical wards with non-specific abdominal pain. Br J Surg 81: 1216-1218.

12. Brunekreef B, Holgate ST (2002) Air pollution and health. Lancet 360: 12331242.

13. Gorham ED, Garland CF, Garland FC (1989) Acid haze air pollution and breast and colon cancer mortality in 20 Canadian cities. Can J Public Health 80: 96100.

14. Villeneuve PJ, Chen L, Stieb D, Rowe BH (2006) Associations between outdoor air pollution and emergency department visits for stroke in Edmonton, Canada. Eur J Epidemiol 21: 689-700.

15. Kaplan GG, Dixon E, Panaccione R, Fong A, Chen L, et al. (2009) Effect of ambient air pollution on the incidence of appendicitis. Cmaj 181: 591-597.

16. Kaplan GG, Hubbard J, Korzenik J, Sands BE, Panaccione R, et al. (2010) The Inflammatory Bowel Diseases and Ambient Air Pollution: A Novel Association. Am J Gastroenterol.

17. Vincent R, Kumarathasan P, Goegan P, Bjarnason SG, Guenette J, et al. (2001) Inhalation toxicology of urban ambient particulate matter: acute cardiovascular effects in rats. Res Rep Health Eff Inst: 5-54; discussion 55-62.

18. Last JA, Gohil K, Mathrani VC, Kenyon NJ (2005) Systemic responses to inhaled ozone in mice: cachexia and down-regulation of liver xenobiotic metabolizing genes. Toxicol Appl Pharmacol 208: 117-126.

19. Beamish LA, Osornio-Vargas AR, Wine E (2011) Air pollution: An environmental factor contributing to intestinal disease. J Crohns Colitis 5: 279-286.

20. Lippmann M, Yeates DB, Albert RE (1980) Deposition, retention, and clearance of inhaled particles. Br J Ind Med 37: 337-362.

21. Stieb DM, Szyszkowicz M, Rowe BH, Leech JA (2009) Air pollution and emergency department visits for cardiac and respiratory conditions: a multi-city time-series analysis. Environ Health 8: 25.

\section{Acknowledgments}

Dr. Gilaad Kaplan is a Canadian Institutes of Health Research New Investigator and a Population Health Investigator from Alberta-Innovates Health Solutions. Dr. Rowe's research is supported by a Tier I Century Canada Research Chair in Evidence-Based Emergency Medicine from the Canadian Institutes for health Research through the Government of Canada (Ottawa, Ontario).

\section{Author Contributions}

Conceived and designed the experiments: M. Szyszkowicz GGK M. Storr BR. Performed the experiments: M. Szyszkowicz GGK JF EP M. Storr. Analyzed the data: M. Szyszkowicz GGK JF EP M. Storr. Contributed reagents/materials/analysis tools: RV. Wrote the paper: M. Szyszkowicz GGK M. Storr KM SG BR RV.

22. Sajani SZ, Hanninen O, Marchesi S, Lauriola P (2010) Comparison of different exposure settings in a case-crossover study on air pollution and daily mortality: counterintuitive results. J Expo Sci Environ Epidemiol.

23. National Air Pollution Surveillance Program (NAPS) Website. Available: http:// www.ec.gc.ca/rnspa-naps/. Accessed 2012 September 30.

24. Zemek R, Szyszkowicz M, Rowe BH (2010) Air pollution and emergency department visits for otitis media: a case-crossover study in Edmonton, Canada. Environ Health Perspect 118: 1631-1636.

25. Maclure M (1991) The case-crossover design: a method for studying transient effects on the risk of acute events. Am J Epidemiol 133: 144-153.

26. Thomson EM, Williams A, Yauk CL, Vincent R (2009) Toxicogenomic analysis of susceptibility to inhaled urban particulate matter in mice with chronic lung inflammation. Part Fibre Toxicol 6: 6.

27. Fichna J, Gach K, Perlikowska R, Cravezic A, Bonnet JJ, et al. (2010) Novel endomorphin analogues with antagonist activity at the mu-opioid receptor in the gastrointestinal tract. Regul Pept 162: 109-114.

28. Gach K, do-Rego JC, Fichna J, Storr M, Delbro D, et al. (2010) Synthesis and biological evaluation of novel peripherally active morphiceptin analogs. Peptides 31: 1617-1624.

29. Laird JM, Martinez-Caro L, Garcia-Nicas E, Cervero F (2001) A new model of visceral pain and referred hyperalgesia in the mouse. Pain 92: 335-342.

30. Eijkelkamp N, Kavelaars A, Elsenbruch S, Schedlowski M, Holtmann G, et al. (2007) Increased visceral sensitivity to capsaicin after DSS-induced colitis in mice: spinal cord c-Fos expression and behavior. Am J Physiol Gastrointest Liver Physiol 293: G749-757.

31. Guthery SL, Hutchings C, Dean JM, Hoff C (2004) National estimates of hospital utilization by children with gastrointestinal disorders: analysis of the 1997 kids' inpatient database. J Pediatr 144: 589-594.

32. Longstreth GF, Thompson WG, Chey WD, Houghton LA, Mearin F, et al. (2006) Functional bowel disorders. Gastroenterology 130: 1480-1491.

33. Heitkemper MM, Jarrett ME (2008) Update on irritable bowel syndrome and gender differences. Nutr Clin Pract 23: 275-283.

34. Ladwig KH, Marten-Mittag B, Formanek B, Dammann G (2000) Gender differences of symptom reporting and medical health care utilization in the German population. Eur J Epidemiol 16: 511-518.

35. Bertakis KD, Azari R, Helms LJ, Callahan EJ, Robbins JA (2000) Gender differences in the utilization of health care services. J Fam Pract 49: 147-152.

36. Roth RP, Tansy MF (1972) Effects of gaseous air pollutants on gastric secretomotor activities in the rat. J Air Pollut Control Assoc 22: 706-709.

37. Kish L, Hotte N, Cheng E, Rioux KP, Kaplan GG, et al. (2011) Orally Ingested Urban Particulate Matter Induces a Pro-Inflammatory Response and Decreases Microflora Diversity. Gastroenterology 140: S-46.

38. Sun Q, Wang A, Jin X, Natanzon A, Duquaine D, et al. (2005) Long-term air pollution exposure and acceleration of atherosclerosis and vascular inflammation in an animal model. Jama 294: 3003-3010.

39. Dybdahl M, Risom L, Moller P, Autrup H, Wallin H, et al. (2003) DNA adduct formation and oxidative stress in colon and liver of Big Blue rats after dietary exposure to diesel particles. Carcinogenesis 24: 1759-1766.

40. Tornqvist H, Mills NL, Gonzalez M, Miller MR, Robinson SD, et al. (2007) Persistent endothelial dysfunction in humans after diesel exhaust inhalation. Am J Respir Crit Care Med 176: 395-400.

41. Bartra J, Mullol J, del Cuvillo A, Davila I, Ferrer M, et al. (2007) Air pollution and allergens. J Investig Allergol Clin Immunol 17 Suppl 2: 3-8. 